\title{
Analysis of the Changes in Urban Thermal Environments Considering Development Densities (FAR and BCR)
}

\author{
B. Park, K. Oh, and S. Hong
}

\begin{abstract}
Due to recent global climate changes and higher concentrations of populations around the world, cities have been more frequently experiencing phenomena such as heat waves and tropical nights during the summer. This can be said to be the result of the relationship between air temperature increase and thermal comfort degradation. Research on this subject is significance for their impact on the quality of life for urban dwellers as well as for their recommendations on sustainability for future generations. This study selected three analysis areas of the urban thermal environment that have been exacerbated in Seoul. Changes in the present conditions of urban thermal environment and in urban development form and density were analyzed in relation to temperature and thermal comfort. As a result, the temperature of the summer was found to have decreased by an average of $1^{\circ} \mathrm{C}$ while PET also decreased by an average of $0.5{ }^{\circ} \mathrm{C}$ when building coverage ratio(BCR) was reduced by $10 \%$, even though the floor area ratio(FAR) increased due to the changes in urban development form and density. In other words, the building coverage ratio had a greater influence on the urban thermal environment than the floor area ratio, and the reduction of the building coverage ratio improved the urban thermal environment. This was judged to be due to the influence of wind path and building shade caused by changes in form, size, and layout of buildings because of the decrease of building coverage ratio. To improve the urban thermal environment in the future, it is necessary to consider wind path and building shadow when establishing medium- and long-term urban planning. The results of the present study can be used as basic data for spatial decision-making of urban planning when considering improvement of the urban thermal environment.
\end{abstract}

Index Terms-Urban thermal environment, urban thermal comfort, urban development form and density.

\section{INTRODUCTION}

Recently, urban dwellers are being increasingly confronted with problems such as tropical nights and heat waves in the summer due to global climate change and higher concentrations of populations. Generally, in the case of urban areas with high population density, the urban thermal environment becoming increasingly exacerbated due to anthropogenic causes alongside growing external temperature. This is cause by the occurrence of the urban heat island phenomenon that involves temperatures of $2^{\circ} \mathrm{C}$ higher than surrounding areas [1]. Rosenzweig (2007) has reported that the temperature of the urban area and its surroundings have differed by about $3^{\circ} \mathrm{C}$ [2], and Akbari et al. (2006) found that the temperature difference between the city and its

Manuscript received October 13, 2017; revised December 7, 2017.

The authors are with the Department of Urban Planning and Engineering, Hanyang University in Seoul, Korea (e-mail: bongchur77@gmail.com, ksoh@hanyang.ac.kr, yeshong@empal.com). surroundings was 2.5 to $4.5^{\circ} \mathrm{C}$ in the United States. As if attesting to the magnitude of the problem, approximately 700 elderly and those who were infirmed perished due to increased urban temperature in Chicago in 1995 [3]. As Korea is not exempt from climate changes, results of an analysis big data by the National Disaster Management Institute predicted that a similar scenario involving a heat wave in the summer of 2020 lasting about 30 days could lead to approximately 10,000 deaths [4]. Needless to say, research that focuses on this subject matter is of great significance not only for the impact on the quality of life of urban dwellers but also for recommendations on the sustainability of future generations.

The ultimate goal of this study is to investigate the degree and cause of exacerbation of the urban thermal environment by analyzing the urban air temperature and comfort level. Subsequently, this research suggests scientific and logical solutions to improve urban thermal comfort.

This study investigated the degree of exacerbation of the urban thermal environment due to changes in urban development form and density through the analysis of air temperature and thermal comfort, and suggests a foundation of improvement direction based on the results.

\section{LITERATURE REVIEW}

\section{A. Concept of Thermal Comfort}

Thermal comfort refers to the balance of the flow of heat absorbed into the human body and its release. Thermal comfort status refers to when skin temperature and perspiration rate are within a thermal comfort range based on metabolic rate.

The main factors affecting the thermal comfort conditions of the human body can be largely divided into two categories. The first one consists of meteorological factors constituting the thermal environment such as air temperature, mean radiant temperature, air velocity, and water vapor pressure in ambient air, etc. Temperature generally refers to the dry bulb temperature, and the mean radiant temperature refers to the uniform blackbody temperature which indicates the exchange of radiant energy that the human body actually feels.

The second factor is the human body thermal equilibrium factors, that involves the activity level, clothing, skin temperature, core temperature, perspiration rate, skin wetting ratio, etc.

\section{B. PET (Physiological Equivalent Temperature)}

The development of thermal comfort indicators was largely accomplished in the early 1990s. Yet, most of thermal 
comfort indicators analyzed the indoor thermal environment. Recently, as the importance of the external thermal environment has emerged, thermal comfort evaluation indicators of the outdoor environment have been developed. Among these indicators, the representative ones are Predicted Mean Vote (PMV), Physiological Equivalent Temperature (PET), Outdoor Standard Effective Temperature (OUT_SET), and Universal Thermal Climate Index (UTCI). This study employed PET, which is widely used around the world and expressed in degrees of Celsius $\left({ }^{\circ} \mathrm{C}\right)$.

PET consists of bioclimatological thermal comfort indicators derived from the energy balance of human body [5]. Matzarakis(2008) defined PET as a necessary theory for human body thermal balance [6], and Mayer(1993) insisted that PET is an empirical thermal comfort index like discomfort index [7]. Also, Höppe (2000) explained that PET is an appropriate climatological indicator, along with apparent temperature and wind speed cooling effects [8].

PET has the advantage of being able to show more comprehensive results to urban and regional planners with the use of commonly used temperature units $\left({ }^{\circ} \mathrm{C}\right)$ and is frequently used with PMV. (Table I) This can be explained in connection with thermal recognition and the physiological stress index. The thermal stress index was presented in order to explain the degree of feeling hotness even if the temperature is not high such as when humidity is high in the summertime and feeling coldness even if the temperature is not low, as when the wind is strong in the winter time.

TABLE I: THERMAL COMFORT RANGE OF PMV AND PET

\begin{tabular}{|c|c|c|c|}
\hline PMV & PET & $\begin{array}{l}\text { Thermal } \\
\text { perception }\end{array}$ & $\begin{array}{c}\text { Grade of } \\
\text { physiological stress }\end{array}$ \\
\hline & & Very Hot & Extreme Cold Stress \\
\hline \multirow[t]{2}{*}{3.5} & $<41$ & & \\
\hline & & Hot & Strong Cold Stress \\
\hline \multirow[t]{2}{*}{2.5} & 35 & & \\
\hline & & Warm & Moderate Cool Stress \\
\hline \multirow[t]{2}{*}{1.5} & 29 & & \\
\hline & & Slightly Warm & Slight Cool Stress \\
\hline \multirow[t]{2}{*}{0.5} & 23 & & \\
\hline & & Comfortable & No Thermal Stress \\
\hline \multirow[t]{2}{*}{-0.5} & 18 & & \\
\hline & & Slightly Cool & Slight HeatStress \\
\hline \multirow[t]{2}{*}{-1.5} & 13 & & \\
\hline & & Cool & Moderate HeatStress \\
\hline \multirow[t]{2}{*}{-2.5} & 8 & & \\
\hline & & Cold & Strong HeatStress \\
\hline \multirow[t]{2}{*}{-3.5} & $<4$ & & \\
\hline & & Very Cold & Extreme Heat Stress \\
\hline
\end{tabular}

\section{ENVI-Met}

When it comes to the microclimate simulation method for the evaluation of thermal environment, there exists various simulations and programs, and yet the Envi-met simulation has been the most commonly used among them recently. The Envi-met model, which was developed into version 3.1 by Michael Bruse of Germany in 1998, is now available in version 4.0 (http://envi-met.com/). The ENVI-met model is grid-based capable of analyzing the thermal environment up to $2.5 \mathrm{~km}$ in width, $2.5 \mathrm{~km}$ in length, and $300 \mathrm{~m}$ in height. As a microclimate model that considers the interactions of buildings, vegetation, ground surface and atmosphere, this program allows one to foresee the microclimate through simulations of the weather patterns of microscopic spatial sizes.

The main function of ENVI-met is to extract each thermal environmental factor such as temperature, humidity, wind speed etc. for the analysis area of microscopic spatial size through simulations along with weather predictions. Due to these functions, ENVI-met has been widely used for microclimate environment analysis in the District Unit Plan. It is mainly used in studies predicting changes in microclimate after development for the situations [9].

\section{STUDY METHOD}

\section{A. Study Scope}

This study used Seoul as the spatial range and selected the urban development form and density change prediction areas (Jangwi-dong, Jamsil-dong, and Chungjin-dong) among the areas with frequent occurrences of the heat island phenomenon. Seoul is a metropolis with a population of $10,204,057$ people and an area of $605.25 \mathrm{~km}^{2}$. It has a high population density and industrial concentration compared with other cities. Seoul also belongs to a temperate climate: it has an average annual temperature of $12.5^{\circ} \mathrm{C}$, an average August temperature of $25.7^{\circ} \mathrm{C}$, and its maximum temperature reaches about $34.2^{\circ} \mathrm{C}$, indicating the presence of severe urban heat island phenomena. Therefore, Seoul was judged to be the most appropriate spatial range for in this study which is aimed at improving the urban thermal comfort (Fig. 1).

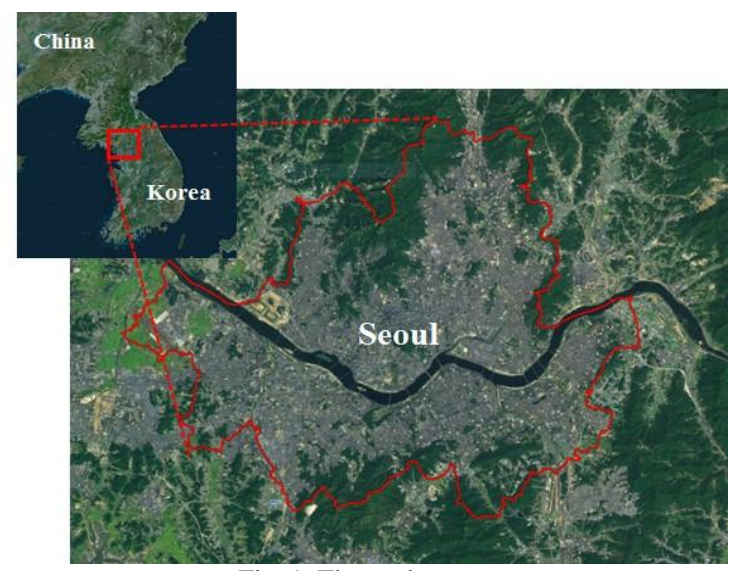

Fig. 1. The study area.

Moreover, considering recent urban environmental problems, serious problems related to the thermal environment are emerging with increasing temperatures in summertime rather than those of wintertime. Therefore, for the time range, the days with general summer weather were selected among June, July and August of 2015 and 2016. In other words, the date of June 10, 2015, which had a relative humidity of $35 \%$ or less, a wind velocity of $3.0 \mathrm{~m} / \mathrm{s}$ or less, and an average temperature of $26.07^{\circ} \mathrm{C}$ or more, was selected. Furthermore, ENVI-met 4.0 was used to analyze the thermal 
environment per analysis areas using PET, which is an indicator of temperature and thermal comfort.

\section{B. Analysis Method}

The analysis process was divided into two parts. The first was urban thermal environment analysis on the present condition of the analysis areas. Temperature and PET were calculated. Second, changes in urban thermal environment were observed by applying changes in urban development form and density to the analysis areas. The changes in urban development form and density were determined considering development plan based on the present condition of the analysis areas. Subsequently, temperature and PET were calculated for each of the three analysis areas after applying the present conditions and the established development plan to each of them. As a result, we compared and examined the analysis results of the urban thermal environment caused by changes in urban development form and density, and determined improvement directions (Fig. 2).

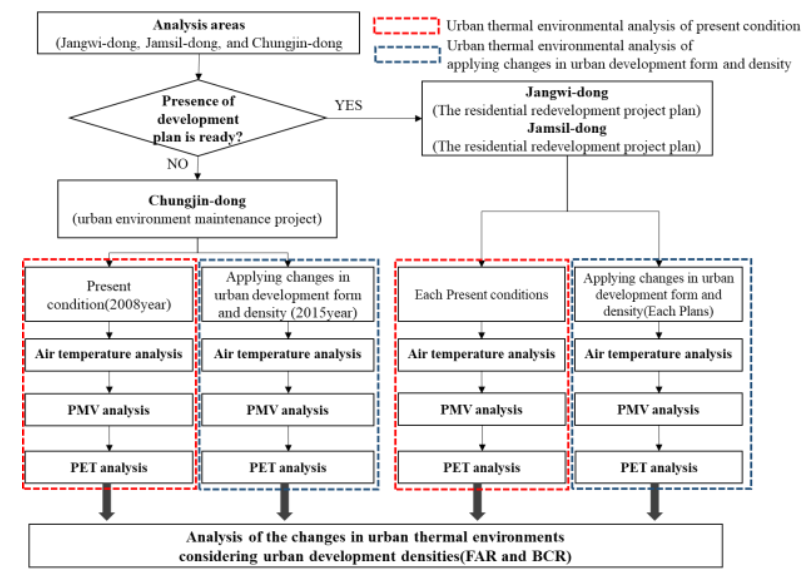

Fig. 2. The framework of urban thermal comfort analysis.

TABLE II: ANALYSIS AREAS

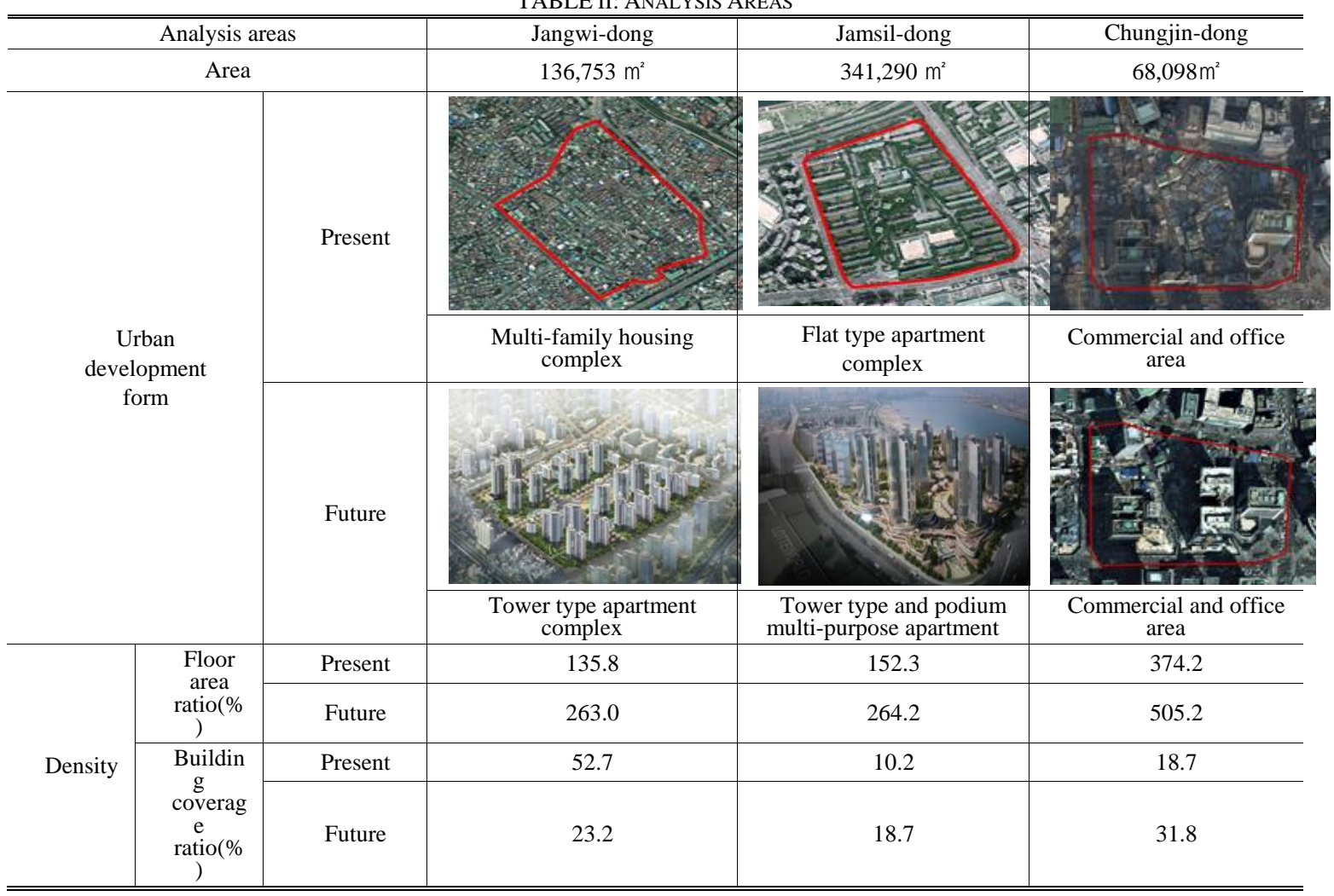

\section{CASE Study}

\section{A. Study Area}

For the analysis areas to be analyzed, the areas where the heat island phenomenon appeared were derived through air temperature analysis of Seoul, and among them, the areas where changes in urban development form and density were predicted were selected in this study (Fig. 3).

As a result, Jangwi-dong, Jamsil-dong, and Chungjin-dong were selected as the analysis areas. First of all, Jangwi-dong was selected for the residential redevelopment project plan in which the areas are planned to be developed into a high-rise high density tower type apartment complex in the low-rise multi-family housing complex. In Jamsil-dong was also selected for, residential redevelopment project plan in which the area will be transformed from being a flat type apartment complex to the tower type and podium multi-purpose apartment complex. Meanwhile, Chungjin-dong is an area undergoing an urban environment maintenance project. As the Chungjin-dong is still currently being transformed, the urban space change was applied in, which the past low-rise commercial area (until 2008) was transformed into having the present high-rise commercial and business facilities (beginning 2015) (TABLE II).

\section{B. Results of Urban Thermal Comfort Analysis}

The results of the analysis of the urban thermal environment in Jangwi-dong revealed that the maximum temperature was $32.08^{\circ} \mathrm{C}$ and the average temperature was $28.08^{\circ} \mathrm{C}$ under present conditions, and in terms of PET, the maximum was $45.24^{\circ} \mathrm{C}$ and the average was $34.84^{\circ} \mathrm{C}$. On the 
other hand, when the plan with changed urban development form and density (124\% increase in floor area ratio and $29 \%$ decrease in building coverage ratio) were applied, the maximum temperature was reduced by $1.81{ }^{\circ} \mathrm{C}$ to stand at $30.27^{\circ} \mathrm{C}$ and the average temperature was reduced by $0.87^{\circ} \mathrm{C}$ to be $27.21^{\circ} \mathrm{C}$ (Fig. 4). Also in terms of PET, the maximum was likewise reduced by $4.30^{\circ} \mathrm{C}$ to stand at $40.94{ }^{\circ} \mathrm{C}$ and the average was reduced by $3.43^{\circ} \mathrm{C}$ to be $34.84^{\circ} \mathrm{C}$ (Fig. 5, 6).

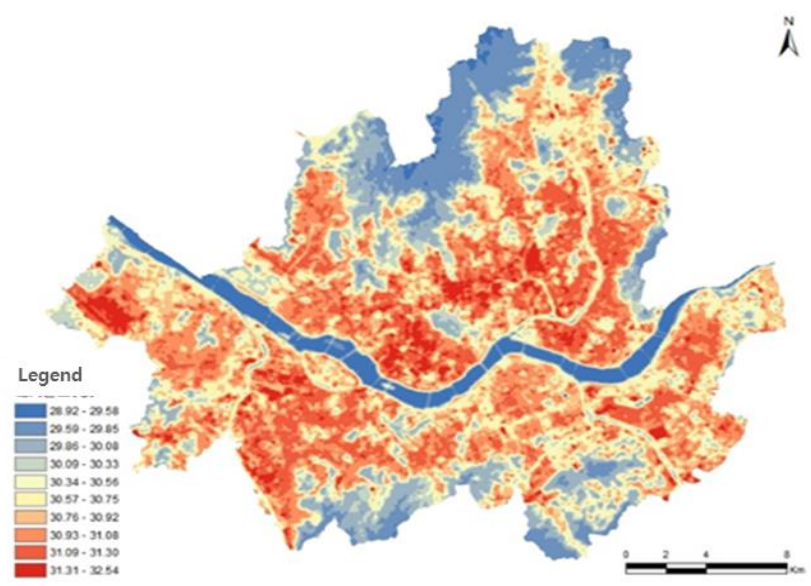

Fig. 3. The result of air temperature analysis in Seoul.

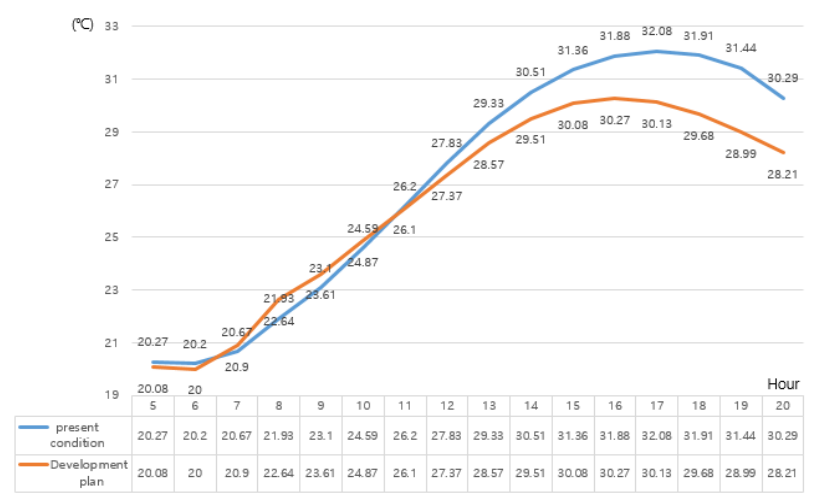

Fig. 4. Air temperature of Jangwi-dong.

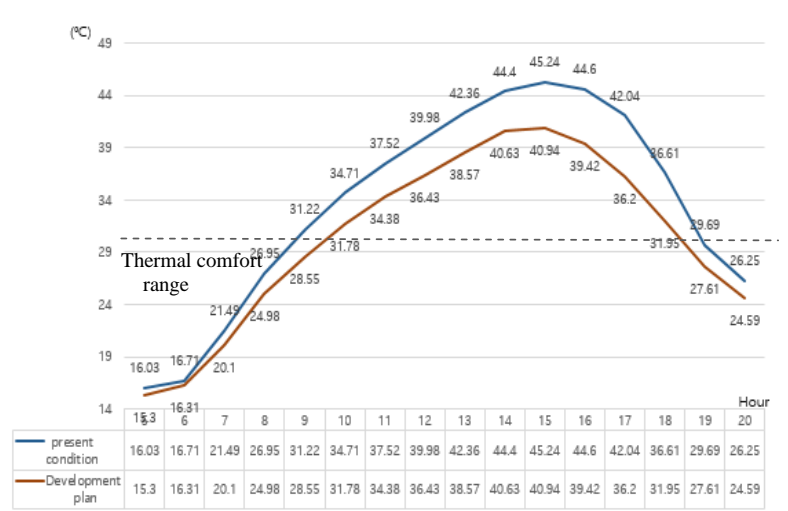

Fig. 5. PET of Jangwi-dong.

In the case of Jamsil-dong the maximum temperature was found to be $32.02^{\circ} \mathrm{C}$ and the average was $28.43^{\circ} \mathrm{C}$ under present conditions. In terms of PET, the maximum was $46.06^{\circ} \mathrm{C}$ and the average was $36.18^{\circ} \mathrm{C}$. On the other hand, when the plan with changed urban development form and density $(111.9 \%$ increase in floor area ratio, $8.5 \%$ increase in building coverage rate) was applied, the temperature was increased by $0.28^{\circ} \mathrm{C}$ to stand at $32.30^{\circ} \mathrm{C}$ and the average was increased by $0.38^{\circ} \mathrm{C}$ to be $28.81^{\circ} \mathrm{C}$, compared with the maximum present condition(Fig. 7). In terms of PET, the maximum temperature was increased by $0.86^{\circ} \mathrm{C}$ to stand at $46.92^{\circ} \mathrm{C}$, and the average temperature was increased by $0.92^{\circ} \mathrm{C}$ to be $37.10^{\circ} \mathrm{C}$, compared with the present conditions (Fig. 8, 9).

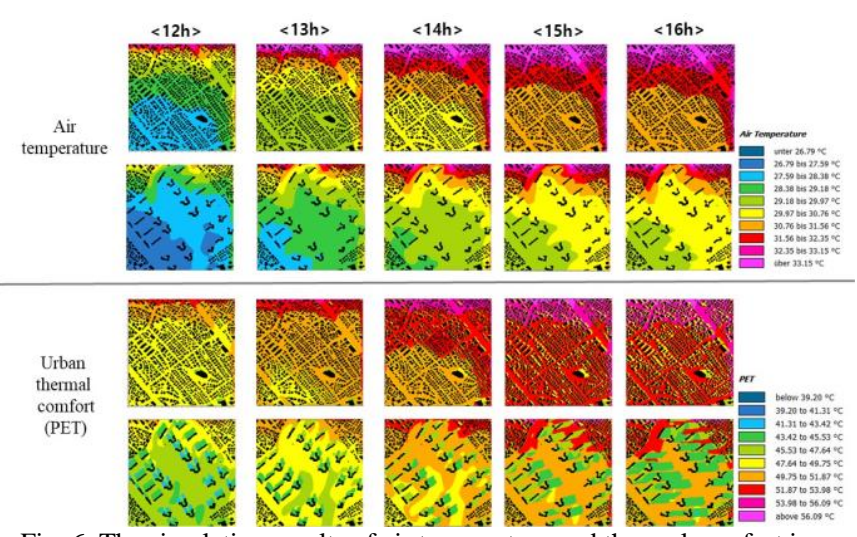

Fig. 6. The simulation results of air temperature and thermal comfort in Jnagwi-dong.

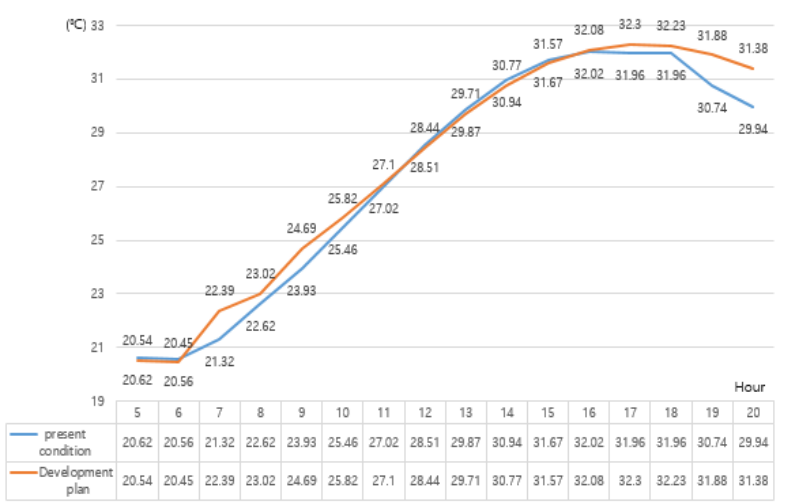

Fig. 7. Air temperature of Jamsil-dong.

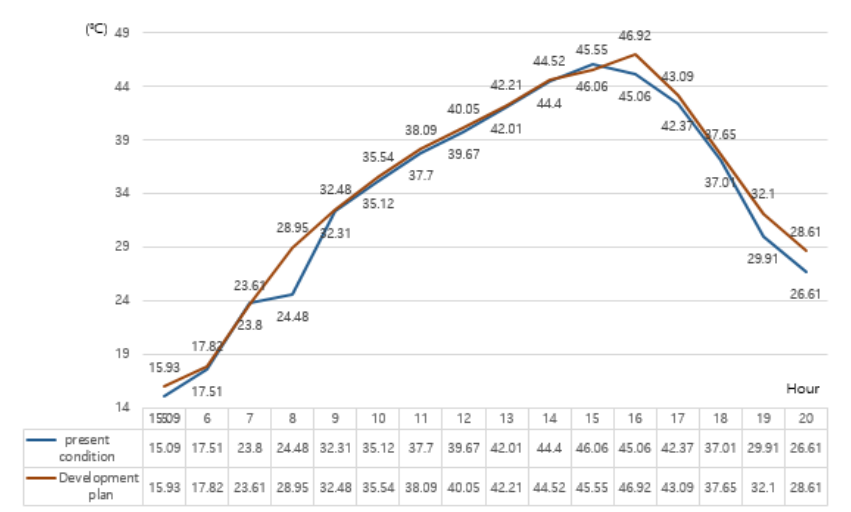

Fig. 8. PET of Jamsil-dong.

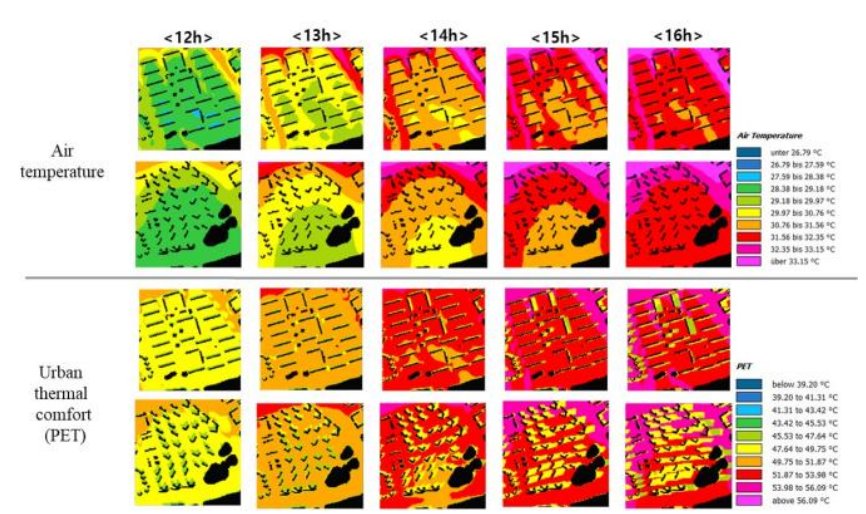

Fig. 9. The simulation results of air temperature and thermal comfort in Jamsil-dong. 
In the case of Jamsil-dong, it was the result of the new construction of the podium multi-purpose apartment area with a relatively large building coverage ratio. However, as a result of the detailed analysis of space, the areas, where the building coverage ratio of the complex inside was reduced, showed a tendency of thermal environment improvement like other areas.

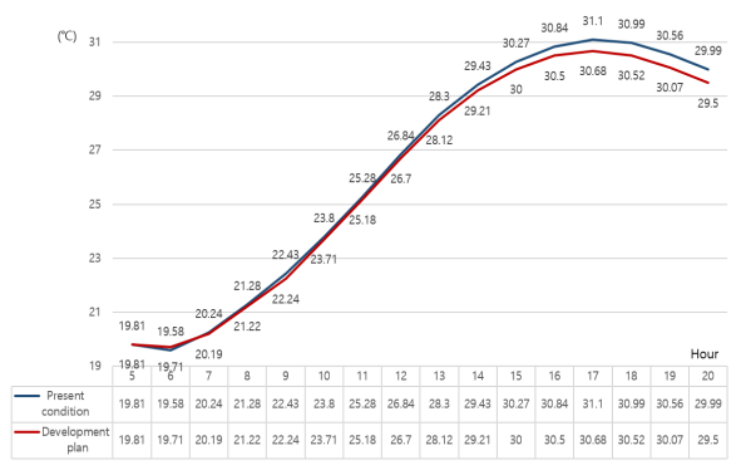

Fig. 10. Air temperature of Chungjin-dong.

In the case of the temperature of June 10, 2008, in the Chungjin-dong, the maximum was $31.1^{\circ} \mathrm{C}$ and the average $26.29^{\circ} \mathrm{C}$, and in terms of PET, the maximum was $41.31^{\circ} \mathrm{C}$ and the average was $31.44^{\circ} \mathrm{C}$. However, in the case of the present conditions (June 10, 2015) when urban development form and density have been changed (131\% increase in the floor area ratio, $14 \%$ decrease in the building coverage ratio), the maximum temperature was decreased by $0.42^{\circ} \mathrm{C}$ to be $30.48^{\circ} \mathrm{C}$ and the average was decreased by $0.2^{\circ} \mathrm{C}$ to be $26.09^{\circ} \mathrm{C}$ (Fig. 10). In terms of PET the maximum temperature was reduced by $0.44^{\circ} \mathrm{C}$ to be $40.87^{\circ} \mathrm{C}$ and the average was reduced by $0.43^{\circ} \mathrm{C}$ to be $31.01^{\circ} \mathrm{C}$ compared with the present condition (Fig. 11, 12).

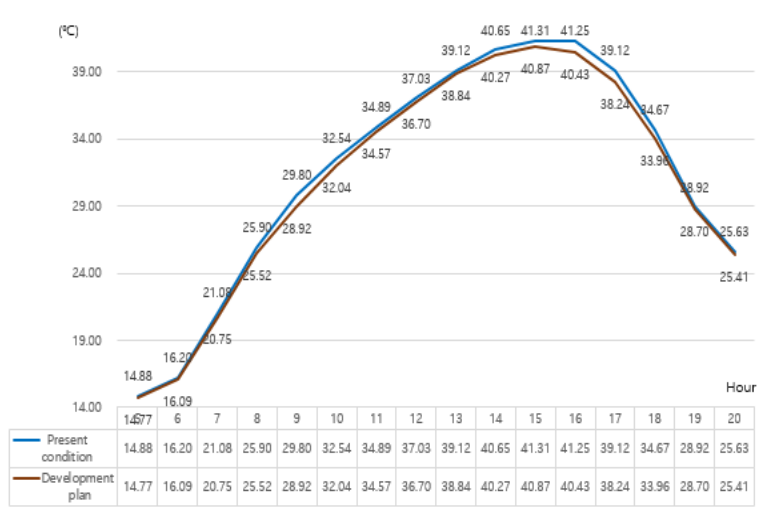

Fig. 11. PET of Chungjin-dong.

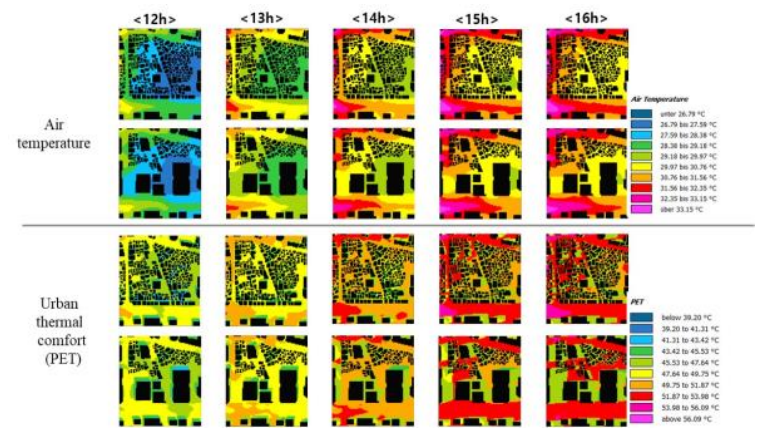

Fig. 12. The simulation results of air temperature and thermal comfort in Chungjin-dong.
Thus far, this study analyzed the changes of the thermal environment in relation to changes in urban development form and density of Jangwi-dong, Jamsil-dong, and Chungjin-dong. The maximum temperature time was $16 \mathrm{~h}$, $17 \mathrm{~h}$ in all analysis areas. And the thermal comfort range time were $05 \mathrm{~h}$ to $09 \mathrm{~h}, 19 \mathrm{~h}$ to $20 \mathrm{~h}$ and midnight.

As a result, when the development capacity increases, the urban thermal environment does not necessarily exacerbate. In other words, even if the floor area ratio increase, the decrease of the building coverage ratio reduces the air temperature and improves the thermal comfort.

\section{CONCLUSION}

In general, it is predicted that if urban development capacity increases, the urban thermal environment will exacerbate. However, the results of this study's analysis on air temperature and urban thermal comfort caused by changes in urban development form and density has revealed that the thermal environment actually improves when the building coverage ratio decreases even if the floor area ratio increases.

Furthermore, it was found that the reduction of building coverage ratio leads to a change in the form, size, and disposition of the buildings, which improves the urban thermal environment when wind paths and shadows are secured. Therefore, considering the influences of wind paths and shadows for urban development form and density adjustment is a very significant factor for improving the thermal environment in urban planning. When establishing medium- and long-term urban planning it is necessary to consider wind paths and shadows for the sustainability of future generations through the improvement of the urban thermal environment.

\section{ACKNOWLEDGMENTS}

This research was supported by a grant (17AUDP-B102406-03) from the Architecture \& Urban Development Research Program (AUDP) funded by the Ministry of Land, Infrastructure and Transport of the Korean government.

\section{REFERENCES}

[1] H. Takebayashi and M. Moriyama, "Study on the urban heat island mitigation effect achieved by converting to grass-covered parking," Solar Energy, vol. 83, pp. 1211-1223, August, 2009.

[2] C. Rosenzweig, W. Solecki, and R. Slosberg, "Mitigating New York City's heat island with urban forestry, living roofs and light surfaces," New York: New York State Energy Research and Development Authority, January, 2007.

[3] S. Konopacki and H. Akbari, "Energy savings for heat island reduction strategies in Chicago and Houston (including updates for Baton Rouge," Sacramento, and Salt Lake City). Draft Final Report, LBNL-49638, University of California, Berkeley, 2002.

[4] J. Lee, J. Jung, D. Kim, H. Kim, J. Won, D. Kim, J. Won, J. Park, and J. Park, "Future safety issue," Seoul, National Disaster Management Institute in Korea, December, 2014.

[5] P. Höppe, "Different aspects of assessing indoor and outdoor thermal comfort," Energy and Buildings, vol. 34, pp. 661-665, July, 2002.

[6] A. Matzarakis and B. Amelung, "Physiological equivalent temperature as indicator for impacts of climate change on thermal comfort of humans," Climatic Change and Human Health, pp. 161-172, February, 2008.

[7] H. Mayer, Urban Bioclimatology, Experientia 49, Birkhäuser Verlag, Switzerland, pp. 957-963, 1993, 
[8] P. Höppe, "The physiological equivalent temperature (PET): An example of a state-of-the-art outdoor thermal comfort index," presented at Internet Workshop on Wind chill, 2000.

[9] Envi-met. [Online]. Available: http://envi-met.com/

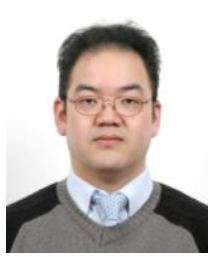

B. C. Park is a Ph. D. candidate in the Department of Urban Planning at Hanyang University in Seoul, Korea. He received his Master's Degree in Urban Planning at Hanyang University for research on improving the Land Suitability Assessment System II. He is currently a researcher of the national $R \& D$ project, Developing the Urban Thermal Environmental Planning and Design System for Adapting Climate Change. His research interests include urban environmental planning, landscape ecology, GIS and spatial analysis, and Climate Change Adaptation.

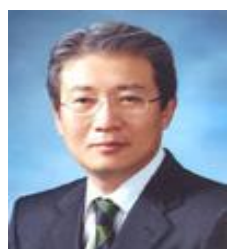

K. S. Ohis a professor in the Department of Urban Planning and Engineering at Hanyang University in Seoul, Korea, where he conducts courses on Environmental Planning, Urban Design, Landscape Analysis, GIS and Urban Spatial Analysis, and Climate Change Adaptation. He completed both his undergraduate and graduate work in Landscape Architecture at Seoul National University and Cornell University, respectively. He received his Ph.D. in Environmental Planning at the University of California, Berkeley. Professor Oh was a visiting professor for the Center for Advanced Spatial Analysis at the University College London, U. K. His recent works involve investigating the carrying capacity of the urban environment and assessment systems. He is also developing planning approaches to ubiquitous and smart cities. Prof. Oh is currently the principal investigator of a national $R \& D$ project, Developing the Urban Thermal Environmental Planning and Design System for Adapting Climate Changes.

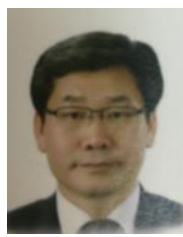

S. D. Hong is a Ph. D. candidate in the Department of Urban Planning at Hanyang University in Seoul, Korea. He received his Master's Degree in Urban Planning at Hanyang University for research on Housing land development. He is currently a director of Korea Land \& Housing Corporation. His research interests include urban environmental planning, landscape ecology, GIS and spatial analysis, and Climate Change Adaptation. 